\title{
ЛИНГВИСТИЧЕСКИЕ И КУЛЬТУРОЛОГИЧЕСКИЕ ТРАДИЦИИ ЯЗЫКОВЫХ И ГЕНДЕРНЫХ ИССЛЕДОВАНИЙ
}

\section{LINGUISTIC AND CULTURAL STUDIES TRADITIONS OF LINGUAL AND GENDER STUDIES}

J-Ch. Aklyan

Summary: Everyday life of people, stereotypes, individual roles and assessment of actions are due to the gender relations. The term "gender" relates to the position of men and women in society, their social and psychological characteristics, and expected norms of behavior. Thereby it is perceived as a "social sex", as despite the biological sex there are various stereotypes and phenomena in real life that are attributed to women or men. Sex reveals the differences between popular cultural stereotypes, changing roles, status, different behaviors, and sensory systems.

The role of gender in language has been carefully studied for over two decades in Western Europe and the United States. Until recently, the researches of the concept of gender in Russian scientific circles were rather indirect, however now there is every reason to believe that genderology in linguistics has taken place as an independent direction.

Keywords: gender, genderology, social sex, linguistics, language, sex, psychology, gender studies, development of genderology.

\author{
Аклян Жан-Кристиан Арменович \\ Аспирант, Московский государственный психолого- \\ педагогический университет \\ jc@aklyan.uk
}

Аннотация: Повседневная жизнь людей, стереотипы, индивидуальные роли и оценка действий во многом обусловлены гендерными отношениями. Термин «гендер» относится к положению мужчин и женщин в обществе, ожидаемым от них нормам поведения, психологическим и социальным характеристикам. В связи с этим он воспринимается как «социальный пол», поскольку помимо биологического пола в общественной жизни существуют различные стереотипы и явления, которые приписывают женщинам или мужчинам. Пол раскрывает различия между популярными культурными стереотипами, меняющимися ролями, статусом, различным поведением и сенсорными системами.

В Западной Европе и Соединенных Штатах роль гендерного фактора в языке тщательно изучалась в течение более двух десятилетий. До недавнего времени исследования концепции гендера в российских научных кругах были скорее косвенными, но теперь есть все основания полагать, что гендерология в лингвистике состоялась как самостоятельное направление.

Ключевые слова: гендер, гендерология, социальный пол, лингвистика, язык, пол, психология, гендерные исследования, развитие гендерологии.

рии: социальный детерминизм и биодетерминизм, которые по-разному описывают гендерные различия.

Как показывает анализ теоретической литературы, для социального детерминизма важна теория когнитивного развития, потому что вся информация о гендерном поведении является отражается в сознании человека в виде гендерных схем. В них присутствуют все, что данный человек знает о гендере. В его сознании формируются гендерные стереотипы, которые влияют на обработку информации [3].

В рамках этого направления особенно подчеркивается тесная связь представлений о мужественности и женственности с коммуникативным поведением. Иначе, они не просто отражаются в языке, а через сознание, формирование которого происходит под влиянием языка [4].

Сторонники концепции гендерного биодетерминизма связывают поведение мужчин и женщин, в частности коммуникативное, с генетической предрасположенностью и результатами процесса развития, подчеркивая презумпцию значительных различий и используя нейрофизиологические данные, психофизиологические различия, тем самым подтверждая различия в структу- 
ре и функции отделов мозга и, следовательно, речевых процессов.

Сторонники этой точки зрения, подчеркивая глобальные различия между двумя полами (физиологические и социальные), приравнивают гендерные различия к половым различиям [5].

Исследование гендерных различий поднимает вопрос учета социальной роли личности в общественной жизни, которая является фактором увеличения или уменьшения различий поведения женщин и мужчин, а также для формирования социальных и гендерных стереотипов $[6,7,8]$.

В разных определениях гендера понятия пола и гендера часто разделяются. Например, Энн Оакли проводит различие между биологическим полом и социальным, объясняя наличие гендерных различий не анатомическими, а особенностями, передаваемыми данному индивиду через культурные элементы [9].

Придавая значение сформированные на основе особенностей мужественности и женственности, некоторые исследователи пытаются полностью игнорировать анатомические и физиологические различия, в то время как О. Рябов принимает понятия пол и гендер с точки зрения целостных отношений. С другой стороны, он считает, что понятие пола включает в себя биологический и социокультурный пол, но в нем нельзя игнорировать социальную составляющую [10].

Быстрое развитие гендерной лингвистики в гуманитарных науках связано с овладением новыми теоретическими положениями. На начальном этапе исследования исследователи сосредоточились на общих методологических вопросах. В последние годы были разработаны различные методологические подходы к гендерным исследованиям, что привело к различному пониманию его сути и дискуссиям среди сторонников биодетерминизма и социального детерминизма. Несовпадение термина гендер в разных языках и культурах, а также последствия несоответствий в межкультурном общении представляют интерес для ученых.

В исследовании гендерных проблем: изученные нами выше различные теории и подходы позволяют заметить, что осознание гендерных различий может играть важную роль в обеспечении взаимопонимания, в частности в рамках данного культурного сообщества.

Гендерные лингвистические исследования должны решать вопросы, связанные с лексикой, синтаксисом, стилистическим разнообразием и использованием невербальных средств.
В рамках культурной традиции язык прежде всего интерпретируется как посредник социальных отношений, выражение социальной идентичности, средство сохранения культурных ценностей, которое наиболее ярко реализуется в общей лингвистике.

Не случайно Ф. Маутнер, который изучал словесное поведение мужчин и женщин в разных социальных группах, считает, что гендерное разнообразие в языке связано с социальными проблемами. Другими словами, влияние социальных условий на развитие языка также отражается в словесных и поведенческих различиях между полами.

Интересно, что первые наблюдения словесных проявлений науки о мужественности и женственности были сделаны путешественниками, но позднее междисциплинарный характер этой проблемы привлек внимание исследователей в различных областях науки. В частности, К. Юнг, связывая понятия мужественности и женственности с мифологическим мышлением, видит в них два внутренних начала, Анимус и Анима [11]. В результате обобщения К. Юнг пытается отделить характеристики мужественности и женственности. По его словам, если мужчина готов к конкуренции, то женщина более склонна к сотрудничеству, если мужчина является воплощением нетерпения, то женщина старается быть терпеливой. Критический дух мужчины противоречит типично для женщин быть согласной и готовность поддержать. По мнению К. Юнг, характерное для мужчин независимость, честолюбие, логичность, рациональность и вспыльчивость противоположны женской уступчивости, нежности и пассивности.

Позже развитие гендерных исследований привело к формированию нескольких основных направлений: 1. гендер как инструмент социального анализа; 2. понимание гендера как инструмента исследования проблем женственности; 3. гендера как культурной интерпретации и т.д.

Различие в использовании мужской и женской речи было отмечено европейскими исследователями, которые посетили западную часть Индии, где мужчинам свойственно использовать многие слова и фразы, которые запрещены для женщин, а мужчины никогда не использовали слова, свойственные женщинам.

В начале двадцатого века интерес к гендерной концепции и языковой коммуникации немного вырос, и тема языка и пола стала одним из научных приоритетов в лингвистике. Этому способствовал ряд обстоятельств. Прежде всего, упомянутый вопрос представлял интерес для всемирно известных лингвистов Э. Сепира, О. Йесперсена, Ф. Маутнера, которые создали ряд направлений в лингвистике двадцатого века. Во-вторых, соци- 
альная жизнь была на первом месте в лингвистических описаниях, и язык считался связанным с обществом и живущим в нем человеком. Также важно отметить, что в области общего языкознания определенная попытка изучить различия между словесными вариантами мужчин и женщин была накоплена на основе так называемых «примитивных языков», и теперь она используется в таких европейских языках, в сфере исследования, как немецком, английском и французском.

В 1913 г. была опубликована работа Ф. Маутнера по языковому анализу, в которой он признал гендерные различия в немецком языке, ссылаясь на социальные и исторические причины. Таким образом, изучая функцию языка в разных социальных сферах, Ф. Маутнеру удалось обнаружить, что, например, среди фабричных рабочих непристойные слова использовались исключительно мужчинами, и что в благородных слоях общества мужчины использовали эвфемизмы вместо ругательств, что было позволено использовать и женщинам. По его словам, женщины чаще используют слова иностранного происхождения, которые ученый объясняет тем, что женщины менее образованны, поскольку им было труднее найти эквиваленты этих слов на своем родном языке. Кроме того, только мужчины могут творчески использовать язык, а женщины осваивают только то, что создано сильным полом. Ученый связывает происхождение «женского языка» с традициями античного театра, где мужчины изначально играли роль женщин. Только после появления женщин на сцене были внесены изменения в технику драматургии, и женщинам была предоставлена возможность «озвучить» свою собственную версию языка. Исторический подход заставил ученого поверить, что общество приняло «язык женщин», когда им было позволено говорить, что свидетельствовало о влиянии гендерного неравенства на публичность языка. Ранее общественное мнение о гендерном разнообразии не принималось во внимание.

Э. Сепир, фокусировавшись на социальных различиях между языками индейских племен, исследует различия в фонетике в пределах одного слога и интерпретирует их как половой сигнал. Он делает вывод, что пол и статус по лингвистической форме предназначают слово отклоняющийся от нормы. Э. Сепир заключает, что пол скрыт в морфологии языков.

В 1922 г. О. Есперсен более широко исследует гендерные особенности языка, основываясь на информацию представителей разных миссий о языках индейских мужчин и женщин, живущих на островах Карибского архипелага. По его словам, женщины использовали слова, которые отличались от мужского словарного запаса. Более того, женщинам было запрещено обращаться к мужчинам по имени. Они были более склонны к эвфемизму, чем к сквернословию и были более консервативными к использованию языка. О. Есперсен также обратил внимание на различия в словесном поведении между мужчиной и женщиной в условиях двуязычия. В двуязычии женщины остаются одноязычными, а мужчины быстро осваивают новый язык [12]. Ученый описал различия и особенности мужского и женского произношения в английской и французской морфологии, лексике, в синтаксических структурах. Хотя и О. Есперсен в свое время, по возможности, полностью прокомментировал влияние гендерного фактора на речевое поведение, но все же его взгляды позже были оспорены на том основании, что его выводы были основаны на собственных субъективных наблюдениях.

Таким образом, первые крупные лингвистические исследования в гендерологии были начаты в 1960-х г. наряду с развитием общей лингвистики, и вниманию были удостоены культурные факторы, которые влияют на речевое и языковое образование. Среди них были выделены характеристики говорящего и собеседника, такие как возраст, пол, социальный статус. В. Лабов провел тщательное исследование, который проанализировал размещение пяти фонологических вариантов окончания «-ing» среди мужчин и женщин в Нью-Йорке. Он изучал влияние социального статуса, национальности, пола, возраста и ситуационных факторов. Это было очень важное исследование, поскольку респонденты были представителями среднего класса, обычными городскими жителями, которые были отобраны в соответствии с полом, возрастом, социальным статусом. Речь каждого респондента анализировалась в различных обстоятельствах, формальных и неформальных, с учетом нескольких факторов одновременно: лингвистического, социального и ситуационного. Это исследование привело к научному признанию того, что пол является наиболее важным фактором, влияющим на речь.

Во время исследований В. Лабова стало ясно, что женщины предпочитают использовать более распространенные формы произношения, что частота различий между произношением мужчин и женщин в английском значительно уменьшилась по мере увеличения их социального статуса и уровня образования. Аналогичные результаты были получены в исследовании гендерного общения на ряде других европейских языков. Кроме того, В. Лабов доказал, что любой разговорный язык использует переменную форму и не произносит одну и ту же фонетическую версию слова во всех случаях его использования. Этот вывод имел большое научное значение, так как «более ранние работы по гендерным вопросам, как правило, прямо или косвенно содержали доказательства внутренних различий между разговорным дискурсом мужчин и женщин как биологически обусловленного фактора».

Из-за феминистского движения 1970-х годов возник- 
ла новая волна интереса к женской речи. Ряд ученых утверждали, что использование определенных «женских» форм речи отрицательно сказывается на их попытках достичь равного положения в обществе. Такая точка зрения часто встречается в более поздних работах, особенно в работах Р. Лакоффа, в которых в основном рассматриваются общие вопросы, связанные с отражением социального статуса женщины в языке. По словам Р. Лакоффа, в европейских языках женщина обычно представлена в негативном свете. Здесь женщина чаще объект, чем субъект. Ее словесное поведение более неуверенное, чем у мужчин, но в то же время гуманнее и менее агрессивное. По мнению автора, это последствия стереотипа женственности у европейского общества, что воспринимается как снисходительность, компромисс и послушность. И наоборот, женщины, которые говорят и пишут в стиле мужчин, то есть те, кто полон решимости обсудить интересующую их тему, которые могут прервать собеседника в устной речи, используют повелительные стили общения, Р. Лакофф воспринимает как необразованность и мужеподобность. Такую ситуацию он определил, как «женский регистр».

Следует отметить, что исследования Р. Лакоффа вызвали много споров. Автор подвергся критике за то, что основывал свой анализ на собственном понимании и искал причины женской речи исключительно в социальных факторах. Слово мужчины принималось как норма. Было сочтено неприемлемым, что исследование Лакоффа отвлекло исследователей как от более систематического и сложного изучения языка, так и, в частности, от значимости мужской речи. Однако работы Лакоффа сыграли значительную роль во многих исследованиях феномена женской речи. Тема гендерных исследований стала расширяться и привлекать внимание лингвистов с появлением новых данных, что привело к росту профессионального интереса к гендерным исследованиям.

Со временем возник вопрос, можно ли определить универсальный принцип для всех языков, который разделит разговорный язык на мужские и женские версии, или же влияние пола на речь основано на конкретных культурах и обществах. Другими словами, ученые начали искать всесторонность, пытаясь выяснить, во всех ли языках в одинаковых отраслях грамматики используются связанные с половыми различиями говорящего и собеседника формы, или существуют правила для использования в зависимости от конкретного языка. Для выяснения были необходимы данные разных языков.
Относительная непоследовательность и нерегулярный характер исследований, постоянная смена приоритетов в лингвистических исследованиях привели к тому, что вопрос о всесторонности все еще остается открытым.

В русской лингвистике начало гендерных исследований обычно начинается в середине 1990-х годов. Именно в этот период в российской научной литературе появился термин «гендер». И хотя исследования того периода не носили систематического характера и не претендовали на статус научного направления, они не были связаны с теорией общественного структурализма, российские ученые внесли определенный вклад в развитие гендерных исследований.

Особенностью лингвистической гендерологии в русской научной литературе является практическое направление изучения мужской и женской речи. Большое количество работ связано с потребностями криминалистивхеской экспертизы. Они сосредоточены на выявлении и уточнении характеристик мужской и женской речи. Для таких исследований более важно разработать методы, позволяющие уточнить фальсификацию речи противоположного пола. Для решения этой проблемы необходимо иметь четкие проверяемые черты слов мужчины и женщины. Таким образом, по словам Т. В. Гомона, «для того, чтобы прийти к выводу о фальсификации слова противоположного пола, необходимо выяснить, какой комплекс гендерных классификационных характеристик мужской и женской речи бросается в глаза, часто и легко имитируется, а какие черты трудно имитировать» [13].

Существуют три основных подхода к изучению влияния гендерных характеристик на формирование речи языкового индивида. Более того, если первый подход сводится к мужскому и женскому языку, к объяснению исключительно обусловленной социальной природой направлен на выявление семантических различий между речевыми элементами, то общий лингвистический подход женский и мужской язык, с научной точки зрения, приводит к особенностям их речевого поведения, отмечая важность их среднестатистических показателей психоаналитических исследований в поведении женщин и мужчин. Представители третьего подхода в языковом поведении полов подчеркивают когнитивный взгляд на различия. Для них важнее не только выяснить частоту различий, но и создать полные лингвистические модели языковых категорий.

\section{ЛИТЕРАТУРА}

1. Винокур Т.Г., Говорящий и слушающий: Варианты речевого поведения. М.: Наука, 1993.

2. Кирилина А.В., Женский голос в русской паремиологии // Женщина в российском обществе, 1997. 
3. Kohlberg L., The Development of Modes of Thinking and Choices in Years 10 to 16. Ph. D. Dissertation, University of Chicago. 1958.

4. Картушина Е.А., Гендерные аспекты фразеологии в массовой коммуникации. Автореферат дисс. канд. фил. н. Ижевск, 2003.

5. Пиз А., Язык взаимоотношений мужчина - женщина. М.: Изд-во ЭКСМО - ПРЕСС, изд-во ЭКСМО - МАРКЕТ, 2000.

6. Eagly A.H., Sex Differences In Social Behavior// A social-role interpretation. New York: Hellbaum, 1987.

7. Eckes T., Features of Men. Features of Women: Assessing Stereotypic Beliefs About Gender Subtypes // British Journal of Social Psychology. London, 1994.

8. Fishman P., Interaction: The Work Women Do // Social Problems. New York, 1978.

9. Oakley A. Sex, Gender and Society, London:Temple Smith, 1972.

10. Рябов 0.В., Гендерные аспекты межкультурной коммуникации: социально-философский анализ// Гендер как интрига познания: Альманах. М.: Рудомино, 2002.

11. Юнг К.Г., Душа и миф: шесть архетипов. Киев: Государственная библиотека литературы для юношества, 1996.

12. Jespersen 0., The Woman // The Feminist Critique of Language: A Reader Routledge: London, New York, 1998.

13. Гомон Т.В., Исследование документов с деформированной внутренней структурой. Дисс. ... кандидата юридических наук. М., 1990.

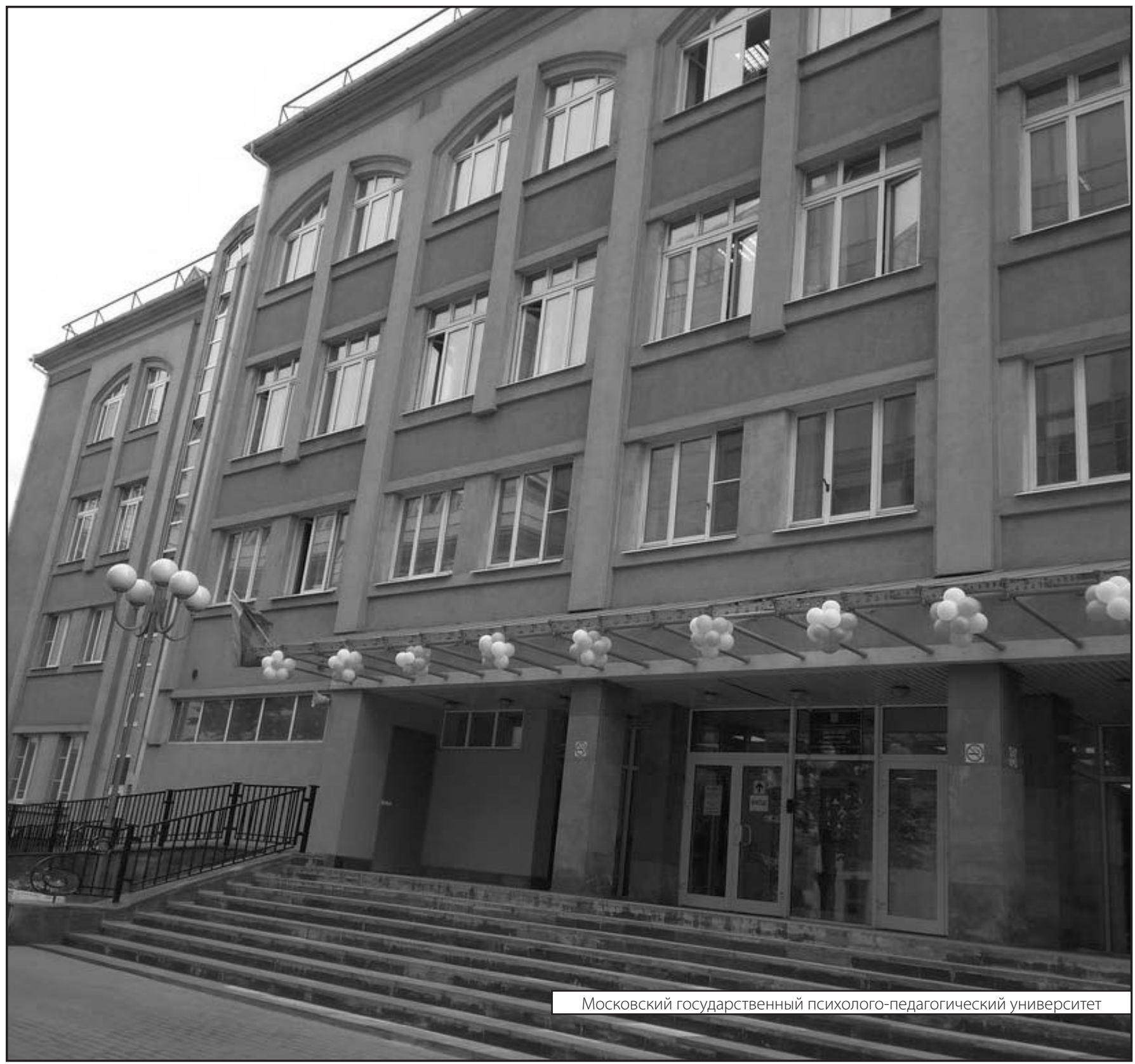

